\title{
Do Changes in Drug Coverage Policy Point to an Increased Role for Cost-Effectiveness Analysis in the USA?
}

\author{
James D. Chambers
}

Published online: 24 May 2014

(C) Springer International Publishing Switzerland 2014

\begin{abstract}
Compared with other countries, cost-effectiveness analysis has traditionally had a limited role in US health care. Rather, US payers have typically accommodated the introduction of expensive technology by passing an increasing proportion of costs to patients, through raising insurance premiums and/or by increasing copayments, coinsurance, and deductibles. However, in what may prove to be a tipping point, the two largest pharmacy benefit managers have chosen to exclude drugs from their formularies that offer uncertain health benefit compared with cheaper alternatives. This paper argues that cost-effectiveness analysis should be used to inform these valuebased decisions, and that by using information other than robust cost-effectiveness evidence, payers risk wrongly denying beneficiaries access to important medical technologies. If cost-effectiveness analysis were to be used in this way, it would be another in a growing number of examples of its use across public and private payers. In the absence of a centralized agency conducting cost-effectiveness analysis, the recently inaugurated 2nd Panel on Cost-Effectiveness in Health and Medicine has an important role to play in standardizing methods and promoting best practice.
\end{abstract}

J. D. Chambers $(\square)$

The Center for the Evaluation of Value and Risk in Health, Institute for Clinical Research and Health Policy Studies, Tufts Medical Center, Boston, MA, USA

e-mail: JChambers@tuftsmedicalcenter.org

\section{Key Points for Decision Makers}

In US health care, payers have typically accommodated expensive technology by shifting costs to patients, and by so doing have largely avoided the trade-offs necessary when choosing which medical technologies to pay for from a limited budget.

However, recent implementation of formularies that exclude drugs deemed to provide questionable added health benefit over more affordable alternatives signal a change in behavior.

Cost-effectiveness analysis is an invaluable tool for payers seeking to judge whether additional health benefits are worth the additional cost.

While there have been many calls for its introduction, cost-effectiveness evidence has traditionally had a marginal role in US health care [1-5]. Much has changed since these calls, and the Accountable Care Act has brought about a number of fundamental changes, among them the promise of payment reform and comparative effectiveness research. Despite these developments, payers continue to face the challenge of paying for the introduction of expensive medical technology.

In general, payers have paid for expensive technology, and have accommodated the introduction of new expensive technology, by raising insurance premiums and by shifting an increasing proportion of costs to the patient through copayments, coinsurance, and deductibles [5-8]. By doing so, payers have largely avoided the need to consider 
explicitly and openly opportunity cost, and the difficult trade-offs necessary when choosing which medical technologies to pay for from a limited budget. However, recent examples of changes to drug coverage policy signal that payers may now be more inclined to make such choices more apparent, and may indicate an important role for cost effectiveness.

For example, on January 1, 2014, Express Scripts, the country's largest pharmacy benefit management (PBM) organization, implemented a "not covered list" of 44 drugs deemed to provide no added health benefit over more affordable alternatives $[9,10]$. The list is part of Express Scripts' recommended national formulary, and will send ripples through US health care, with 30-40 million beneficiaries affected. The list includes both newer and older drugs for a range of indications, including diabetes, multiple sclerosis, and cardiovascular disease. Various major brand name drugs are featured, including Advair (fluticasone/salmeterol) for asthma and chronic obstructive pulmonary disorder, and Victoza (liraglutide) for type 2 diabetes.

Express Scripts' decision not to cover drugs deemed poor value for money is not unique, but rather the most recent in a growing number of noteworthy examples of payers and providers' refusal to cover drugs of limited value unchecked. In 2012, CVS Caremark, the country's second largest PBM, excluded from their formulary 37 drugs they considered no more effective than cheaper alternatives [11]. While unlike Express Scripts' list, CVS Caremark's did not include the same notable brand name drugs, e.g., no biologics were included, an additional 25 products have been excluded from the 2014 formulary, a move expected to lead to US $\$ 1$ billion in annual savings $[12,13]$.

Express Scripts and CVS Caremark's decision to exclude these drugs is in response to rising prices, and manufacturers' growing practice of issuing co-pay cards to cover the cost of patients' copayments. By issuing these cards, manufacturers counteract payers' placement of drugs on higher formulary tiers associated with significant cost sharing as a method of discouraging use of high cost, and often low-value, drugs. Indeed, manufacturers have issued co-pay cards for $93 \%$ of drugs included on Express Scripts' list [14].

It is not only payers who have started to balk at expensive drugs that offer uncertain benefits over alternatives. In summer 2012, the FDA approved ziv-aflibercept $\left(\right.$ Zaltrap ${ }^{\circledR}$ ) for advanced colon cancer. In a landmark decision, the Memorial Sloan-Kettering Cancer Center chose not to use the drug-costing approximately US $\$ 11,000$ per month-because it proved no better than existing treatments that were half the cost [15]. In response, the manufacturer halved the cost of the drug [16].
Common among the above examples is that the decision to not cover or pay for a drug was largely based on its perceived lack of value relative to alternative therapeutic options, and not solely due to its high cost. While unclear if cost-effectiveness evidence was used in the above examples, it is precisely for such decisions that such evidence is invaluable. Cost-effectiveness analysis is the only technique that quantifies the relative value of competing treatments by estimating the additional cost of generating an additional unit of health outcome, e.g., depression free day, or life-year gained. In doing so, cost-effectiveness analysis provides information that allows the decision maker to judge whether the additional benefit is worth the additional cost. While comparative effectiveness research provides valuable information on the relative clinical effectiveness of competing treatments, the exclusion of costs means that the information is insufficient for those seeking to judge relative value. By basing a decision not to cover a technology because of a lack of value for money on information other than robust cost-effectiveness evidence, the payer risks making an incorrect decision and wrongly denying beneficiaries access to important medical technologies. Relying on a crude estimate of cost effectiveness may not fully account for important economic benefits, e.g., a reduction in costly hospitalizations associated with adverse events, leading to a false impression of a drug's value. If cost-effectiveness analysis were to be formally introduced to aid this type of decision making, the US health care system would not be starting from scratch. While far from used routinely, cost-effectiveness evidence is used by some public and private payers in the US.

Among public payers, the Department of Veterans Affairs and the Department of Defense have research centers that, among other things, perform cost-effectiveness analysis of medical care $[17,18]$. Further, the state of Washington's health technology assessment program performs cost-effectiveness analysis as part of its attempts to ensure that state-purchased health care is safe, effective and worth the cost [19]. Notably, Medicare, a payer that famously excludes cost and cost-effectiveness considerations from deliberations for new treatments, often reviews cost-effectiveness evidence in national coverage determinations for preventive interventions [20-24].

With respect to the private insurance market, the Academy of Managed Care Pharmacy (AMCP), the national professional society for pharmaceutical care in managed health care markets, has issued guidelines for including cost-effectiveness evidence in formulary submissions [25]. The health plans Wellpoint and Premera Blue Cross are among those that use cost-effectiveness evidence. Wellpoint, a major for-profit company in the Blue Cross and Blue Shield Association, has issued their own guidelines for how industry should conduct and 
present cost-effectiveness evidence in their formulary dossiers [26]. Premera Blue Cross, a nonprofit health plan, uses cost-effectiveness evidence to assign more costeffective treatments to lower tiers in their value-based formulary [27].

But while the above examples should provide encouragement for those that champion cost effectiveness, it is unlikely the USA will soon embrace it in a similar manner to countries like the UK, Australia, and Canada [5]. For starters, these countries have established health technology assessment agencies responsible for assessing medical technology, an aspect of which is to determine cost effectiveness relative to alternative care [28]. US health care is arguably less suited to a centralized agency conducting cost-effectiveness analysis than other countries. The US health care system is an amalgamation of multiple public and private payers, each covering a unique patient population with specific health care needs, with separate budgets and independent criteria for judging coverage of medical technology [29, 30]. With this degree of fragmentation, it would be hugely difficult for a centralized agency to conduct cost-effectiveness analyses that simultaneously address the needs of all parties.

While such a body would have obvious benefits, including standardization of methods, and autonomy from vested interests, it would garner little support from society. A recent US public opinion study found that approximately $56 \%$ of respondents opposed a government agency performing cost-effectiveness analyses [31]. The hostility that has met the impending Independent Payment Advisory Board - a body charged with reducing net growth of Medicare spending - offers another indication, with claims its actions would be tantamount to governmental 'death panels' [32].

The discomfort with cost effectiveness and the rationing of health care was evident in the 2010 Affordable Care Act's creation of the Patient-Centered Outcomes Research Institute. Created to conduct and promote comparative effectiveness evidence, the institute is barred from using cost per quality-adjusted life-year (QALY) thresholds, and it has visibly distanced itself from costs and cost effectiveness in its research [33-35].

The lack of a centralized agency has meant that use of cost effectiveness has grown organically in US health care. As described above, while not used extensively, cost effectiveness is used in various parts of the health care system to address specific payer problems. Express Scripts and CVS Caremark's predicament of whether to cover drugs of questionable value offers another opportunity for cost effectiveness to play an important role.

In the absence of a centralized cost-effectiveness agency, the recently inaugurated 2nd Panel on CostEffectiveness in Health and Medicine is hugely important
[36]. The US Public Health Service convened the original panel in 1993 and tasked it to assess the state of the science of cost-effectiveness analysis. Their recommendations for the conduct of cost-effectiveness studies issued in 1996 are thought to have had a positive impact on the field, if followed somewhat inconsistently [37-40].

The new panel has the opportunity to serve as a national unifying template for the conduct of cost-effectiveness analysis. Its recommendations should not only help standardize methods, but also recognize the heterogeneity with which cost-effectiveness analysis is used across the health care system. While a reference case, i.e., specification of the set of recommended methods for cost-effectiveness analysis, may be featured again in its recommendations, the panel's guidance should ideally include flexibility to allow practitioners of cost effectiveness to apply the approach to their specific situations, while maintaining methodological rigor.

To this end, the new panel's recommendations should follow the lead of the original panel and not be too prescriptive. For instance, while taking a societal perspective in cost-effectiveness analysis comprehensively accounts for all health effects and economic consequences of using a technology, and may be most relevant to a public payer like Medicare, it is unlikely to be the most relevant perspective for a for-profit health plan. Further, whereas use of the QALY aids the UK's National Institute of Health and Care Excellence account for opportunity cost as it allocates scarce resources across technologies and indications, it does not have the same application to a US health plan using cost-effectiveness analysis to prioritize drug coverage within a specific indication.

Cost-effectiveness evidence's future role in US health care may hinge in part on the success of payment reform in slowing the growth of health care costs [41]. Two key payment reforms are bundled payments, or episode-based payments, and Accountable Care Organizations (ACOs), approaches that spread financial risk across payers and providers to incentivize efficient health care delivery. In bundled payments, or episode-based payments, providers receive a fixed payment for delivering a defined episode of care, e.g., the recently expanded bundle for end-stage renal disease [42]. Providers make a profit if care is delivered at a cost less than the fixed payment, but may incur a penalty if delivered care costs more [43]. Accountable Care Organizations are broader in scope and consist of groups of health care providers. An ACO receives a fixed payment for delivering care to a group of patients over a defined time period, and, similar to bundled payments, profitability is tied to the efficiency of care delivery [44].

While expanded prospective payment systems or global capitation arrangements do not affect coverage of technology per se, in theory they should encourage cost- 
effective use of it. They do not, however, fully address the challenge of whether and how to pay for expensive new technology with uncertain benefits over existing alternatives: the challenge faced by Express Scripts and CVS Caremark. While payment reform offers great promise, it remains to be seen if it will prove sufficient to fully put health care spending on a sustainable path.

The recent introduction of sofosbuvir $\left(\right.$ Sovaldi $\left.^{\circledR}\right)$, a major advancement in the treatment of hepatitis C, underscores the challenge facing payers. At a cost of US\$84,000 for a 12-week course of therapy, and with an estimated 3.2 million hepatitis C patients in the USA, concerns about its potential impact on health care budgets have been voiced [45-47]. Express Scripts and CVS Caremark's decisions to exclude drugs from their formularies should be a warning about the seemingly unavoidable ethical and financial challenges payers will increasingly confront when judging coverage of technology. The concept of opportunity cost has historically played a limited role in US decision making, as rather than being compelled to choose which technologies to cover from a limited budget, payers have accommodated existing and new expensive technology by shifting costs to patients. We may now have reached the tipping point, with some payers unwilling to transfer a greater portion of costs to the patient in order to pay for technology of questionable value.

Cost-effectiveness analysis provides exactly the information payers require to judge the relative value of competing interventions, and the opportunity cost of their decisions. We should hope that payers choose to use well performed cost-effectiveness studies to inform these critical decisions. If this proves to be the case, cost-effectiveness analysis may have found a new and important role in US health care.

Conflicts of interest The author declares no conflicts of interest.

\section{Reference}

1. Leaf A. Cost effectiveness as a criterion for Medicare coverage. N Engl J Med. 1989;321(13):898-900.

2. Neumann PJ, Rosen AB, Weinstein MC. Medicare and costeffectiveness analysis. N Engl J Med. 2005;353(14):1516-22.

3. Prosser LA, Koplan JP, Neumann PJ, Weinstein MC. Barriers to using cost-effectiveness analysis in managed care decision making. Am J Manag Care. 2000;6(2):173-9.

4. Neumann PJ, Palmer JA, Daniels N, Quigley K, Gold MR, Chao S. A strategic plan for integrating cost-effectiveness analysis into the US healthcare system. Am J Manag Care. 2008;14(4):185-8.

5. Bryan S, Sofaer S, Siegelberg T, Gold M. Has the time come for cost-effectiveness analysis in US health care? Health Econ Policy Law. 2009;4(Pt 4):425-43.

6. Lee TH, Emanuel EJ. Tier 4 drugs and the fraying of the social compact. N Engl J Med. 2008;359(4):333-5.
7. Cunningham PJ. The growing financial burden of health care: national and state trends, 2001-2006. Health Aff (Millwood). 2010;29(5):1037-44.

8. Collins SR, Robertson R, Garber T, Doty MM. Insuring the future: current trends in health coverage and the effects of implementing the Affordable Care Act. The Commonwealth Fund. http://www. commonwealthfund.org/Publications/Fund-Reports/2013/Apr/ Insuring-the-Future.aspx. Accessed 6 April 2014.

9. Express Scripts. 2014 Drugs not covered. https://member. express-scripts.com/images/pdf/2014prefdrugexclusionlist.pdf. Accessed 6 April 2014.

10. Kelly C. Express scripts tightens commercial formulary control with "not covered" list. The Pink Sheet. 7 October 2013.

11. CVS Caremark. Formulary Exclusions 2012. http://www.care mark.com/portal/asset/Formulary_Exclusion_Drug_List_2012. pdf. Accessed 6 April 2014.

12. CVS Caremark. Formulary Drug Exclusions 2014. http://www. caremark.com/portal/asset/cvscaremark_standard_formulary_drug_ removal.pdf. Accessed 6 April 2014.

13. Kelly C. CVS Caremark formulary exclusion program expected to save \$1 bil. In 2014. The Pink Sheet. 20 December 2013.

14. Silverman E. Bye, bye co-pay cards? Why express scripts is excluding dozens of drugs. http://www.forbes.com/sites/edsilv erman/2013/10/21/bye-bye-co-pay-cards-why-express-scripts-isexcluding-dozens-of-drugs/. 21 October 2013. Accessed 6 April 2014.

15. Bach PB, Saltz LB, Wittes RE. In cancer care, cost matters. New York Times. http://www.nytimes.com/2012/10/15/opinion/ahospital-says-no-to-an-11000-a-month-cancer-drug.html?_r=0. 14 October 2012. Accessed 6 April 2014.

16. Pollack A. Sanofi halves price of cancer drug Zaltrap after SloanKettering rejection. http://www.nytimes.com/2012/11/09/business/ sanofi-halves-price-of-drug-after-sloan-kettering-balks-at-payingit.html. 11 August 2012. Accessed 6 April 2014.

17. Department of Veteran Affairs. Department of Veteran Affairs Health Economic Resource Center (HERC). http://www.herc. research.va.gov/home/default.asp. Accessed 6 April 2014.

18. Department of Defense. The Department of Defense (DoD) PharmacoEconomic Center (PEC). http://www.pec.ha.osd.mil/. Accessed 6 April 2014.

19. Washington State. Washington State Health Authority Health Technology Assessment Program. http://www.hca.wa.gov/hta/ Pages/index.aspx. Accessed 6 April 2014.

20. Chambers JD, Neumann PJ. Listening to Provenge-what a costly cancer treatment says about future Medicare policy. N Engl J Med. 2011;364(18):1687-9.

21. Centers for Medicare and Medicaid Services. Decision memo for screening for the human immunodeficiency virus (HIV) infection (CAG-00409N). http://www.cms.gov/medicare-coverage-database/ details/nca-decision-memo.aspx $?$ NCAId $=229 \&$ NcaName $=$ Screen ing +for +the +Human+Immunodeficiency+Virus+\%28HIV\%29 + Infection $\& \mathrm{bc}=$ AiAAAAAACAAAAA $\% 3 \mathrm{~d} \% 3 \mathrm{~d} \&$. Available 8 December 2009. Accessed 6 April 2014.

22. Centers for Medicare and Medicaid Services. Decision memo for screening for depression in adults (CAG-00425N). http://www. $\mathrm{cms}$.gov/medicare-coverage-database/details/nca-decision-memo. aspx ?NCAId $=251 \&$ NcaName $=$ Screening + for + Depression + in + Adults \&bc=AiAAAAAACAAAAA $\% 3 \mathrm{~d} \% 3 \mathrm{~d} \&$. Available 14 October 2011. Accessed 6 April 2014.

23. Centers for Medicare and Medicaid Services. Decision memo for screening and behavioral counseling interventions in primary care to reduce alcohol misuse (CAG-00427N). http://www.cms.gov/ medicare-coverage-database/details/nca-decision-memo.aspx? NCAId=249. Available 14 October 2011. Accessed 6 April 2014. 
24. Neumann PJ, Chambers JD. Medicare's enduring struggle to define "reasonable and necessary" care. N Engl J Med. 2012; 367(19):1775-7.

25. Academy of Managed Care Pharmacy. The AMCP format for formulary submissions version 3.0. J Manag Care Pharm. 2010; 16(1 Suppl A):1-30.

26. Wellpoint Health Technology Assessment Guidelines. Drug submission guidelines for re-evaluation of products, indications, and formulations. National Pharmacy and Therapeutics Committee. 2008. http://www.elsevierbi.com/ /media/Images/Public ations/Archive/The\%20Pink\%20Sheet/70/043/00700430001/well point_formulary_guidelines.pdf. Accessed 6 April 2014.

27. Watkins J, Sullivan SD, Wong E, Yamamoto S, Vogeler C, Ramsey S. Implementing a value-based formulary pilot in a U.S. Commercial Self-insured Group. Presented at the international society for pharmacoeconomics and outcomes research, Baltimore, MD, USA. 2011.

28. Clement FM, Harris A, Li JJ, Yong K, Lee KM, Manns BJ. Using effectiveness and cost-effectiveness to make drug coverage decisions: a comparison of Britain, Australia, and Canada. JAMA. 2009;302(13):1437-43.

29. Cebul RD, Rebitzer JB, Taylor LJ, Votruba M. Organizational fragmentation and care quality in the U.S. health care system. National Bureau of economic research working paper series 2008 August, Working Paper 14212.

30. Elhauge E. The fragmentation of U.S. health care: causes and solutions. Oxford: Oxford University Press; 2010.

31. Botta MD, Blendon RJ, Benson JM. Cost-effectiveness decision making and US public opinion. JAMA Intern Med. 2013;7:10.

32. Orient JM. Is the payment board a death panel? http://www. washingtontimes.com/news/2012/mar/8/is-the-payment-board-adeath-panel/?page=all. Available 3 Aug 2012.

33. The Patient Protection and Affordable Care Act, PL 111-148. 3-23-2010.

34. Selby J. Straight talk with...Joe Selby. Nat Med. 2012;18(8): 1164.

35. Neumann PJ, Weinstein MC. Legislating against use of costeffectiveness information. N Engl J Med. 2010;363(16):1495-7.
36. The 2nd Panel on Cost-Effectiveness in Health and Medicine. http://2ndcep.hsrc.ucsd.edu/ (2014). Accessed 6 April 2014.

37. Gold MR, Siegel JE, Russell LB, Weinstein MC. Cost-effectiveness in health and medicine. New York: Oxford University Press; 1996.

38. Russell LB, Gold MR, Siegel JE, Daniels N, Weinstein MC. The role of cost-effectiveness analysis in health and medicine. Panel on cost-effectiveness in health and medicine. JAMA. 1996; 276(14):1172-7.

39. Siegel JE, Weinstein MC, Russell LB, Gold MR. Recommendations for reporting cost-effectiveness analyses. Panel on costeffectiveness in health and medicine. JAMA. 1996;276(16): 1339-41.

40. Phillips KA, Chen JL. Impact of the U.S. panel on cost-effectiveness in health and medicine. Am J Prev Med. 2002;22(2): 98-105.

41. Cutler D. Analysis \& commentary. How health care reform must bend the cost curve. Health Aff (Millwood). 2010;29(6):1131-5.

42. Chambers JD, Weiner DE, Bliss SK, Neumann PJ. What can we learn from the U.S. expanded end-stage renal disease bundle? Health Policy. 2013;110(2-3):164-71.

43. Miller HD. From volume to value: better ways to pay for health care. Health Aff (Millwood). 2009;28(5):1418-28.

44. McClellan M, McKethan AN, Lewis JL, Roski J, Fisher ES. A national strategy to put accountable care into practice. Health Aff (Millwood). 2010;29(5):982-90.

45. Institute for Clinical and Economic Review. The comparative clinical effectiveness and value of simeprevir and sofosbuvir in the treatment of chronic hepatitis C infection. http://ctaf.org/sites/ default/files/assessments/CTAF_Hep_C_Apr14_final.pdf (2014). Accessed 15 April 2014.

46. Centers for Disease Control. Hepatitis C FAQs for health professionals. http://www.cdc.gov/hepatitis/c/cfaq.htm (2014). Accessed 6 April 2014.

47. Reinhardt UE. The dollar value of an extra year of life. New York Times, 28 March 2014. http://economix.blogs.nytimes.com/2014/ 03/28/the-dollar-value-of-an-extra-year-of-life/?_php=true\&_ type=blogs\&_r=0. Accessed 6 April 2014. 